\title{
The effect of wind direction on drift control by snow fences
}

\author{
Yukari Takeughi, ${ }^{1 *}$ Shun'ichi Kobayashi, ${ }^{1}$ Takeshi Sato, ${ }^{2}$ Kaoru Izumi, ${ }^{1}$ Kenji Kosugi, ${ }^{2}$ Wang Xin, ${ }^{1}$ \\ Zhang Jiapin, ${ }^{3}$ Peng Yongheng ${ }^{3}$ \\ ${ }^{1}$ Research Institute for Hazards in Snowy Areas, Niigata University, Niigata 950-2181, Japan \\ ${ }^{2}$ Shinjo Branch of Snow and Ice Studies, National Institute of Earth Science and Disaster Prevention, Shinjo 996-0091, Japan \\ ${ }^{3}$ Heilongjiang Communications College, Harbin 150050, China
}

\begin{abstract}
Snowdrifting processes and the wind-velocity profiles around a collector and a blower snow fence were investigated in a cold wind tunnel. The purpose was to ascertain the effect of wind direction on drift control by snow fences. Three different cases were studied for both types of snow fence, and the resultant snowdrifts were compared. In the first case, the snow fence was perpendicular to the wind direction. In the second and third cases, it was tilted by $30^{\circ}$ and $45^{\circ}$. When the collector snow fence was tilted, the amounts of snowdrift were much less than when the fence was perpendicular to the wind direction, because the area with low wind velocity was reduced to half behind the tilted fence. On the other hand, the blowing effect of the blower snow fence increased when it was set up at an angle to the wind direction. It is necessary to investigate the position where the blown snow is deposited by the tilted blower snow fence.
\end{abstract}

\section{INTRODUCTION}

The snow-carrying capacity of the wind is approximately proportional to the cube of its velocity, so even a small reduction in velocity may produce substantial deposits of snow (Verge and Williams, 1981). For example, roads, railways and buildings may decrease wind velocity and cause a snowdrift. The most common method of drift control is to set snow fences, of which there are two types, the collector snow fence and the blower snow fence. The former decreases wind velocity and deposits snow on its leeward side. The latter increases wind velocity and blows off the snow on its leeward side.

The effect of snow fences set up perpendicular to the wind direction has been studied by many researchers, going back many years. Field investigations were carried out by, among others, Shiotani (1967), Wang and Chen (1980), Verge and Williams (1981), Naruse (1982) and Takeuchi and others (1984). Anno and Konishi (1981) carried out wind-tunnel experiments using clay particles, and Anno (1984) proposed six similarity requirements for snowdrift modeling. Uematsu and others (1991), among others, studied snowdrift by threedimensional numerical simulation. However, there are few studies on the effect of wind direction on drift control by snow fences. In this study, the snowdrifting process around snow fences was investigated in a cold wind tunnel. The focus was on the formation of snowdrift by collector and blower snow fences under different wind directions.

\section{EXPERIMENTAL METHODS}

The experiment was carried out in a wind tunnel in the large cold room of the Shinjo Branch of Snow and Ice Studies,

\footnotetext{
* Present address: Niigata Experimental Laboratory, Public Works Research Institute, Arai 944-0051, Japan.
}

National Institute of Earth Science and Disaster Prevention (NIED). The test-section length and cross-sectional dimensions of the tunnel are $14 \mathrm{~m}$ and $1 \mathrm{~m} \times 1 \mathrm{~m}$, respectively. A snow-fence model was set at $7.5 \mathrm{~m}$ from the windward end. After that the test section was paved with sieved snow particles. Small amounts of snow particles were supplied with a snow seeder at the windward end. The supplying rate was kept at $350-480 \mathrm{~g} \mathrm{~min}^{-1}$ to maintain a steady snowdrift. The wind velocity of the wind tunnel was set at $7 \mathrm{~m} \mathrm{~s}^{-1}$. The air temperature of the cold room was maintained at $-10^{\circ} \mathrm{C}$.

The drifting snow was not saturated, because the paved snow on the test section was hard (Sato and others, 2001). Measurement of drift was made after it attained equilibrium and the size of snowdrift did not change. The equilibrium lee drifts around snow fences having similar structure are scaled in proportion to fence heights, even in model experiments (Tabler, 1980a, b; Takeuchi and others, 1984). However, the dimension of the lee drift in this experiment was about half of those found by Takeuchi (1989). This may be because the drifting snow was not saturated, as mentioned above.

(a) Collector snow fence

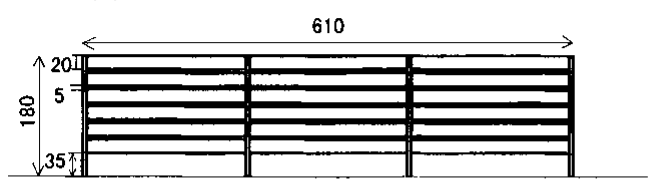

(b) Blower snow fence

610

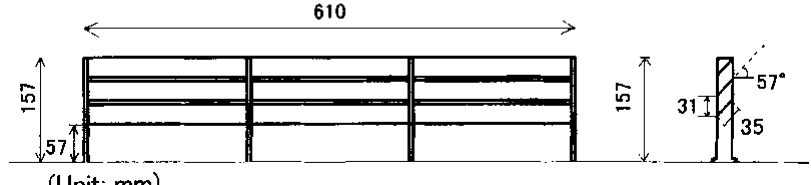

(Unit: $\mathrm{mm}$ )

Fig. 1. Schematic diagram of the snow-fence models used in this experiment. (a) Collector snow fence. (b) Blower snow fence. 


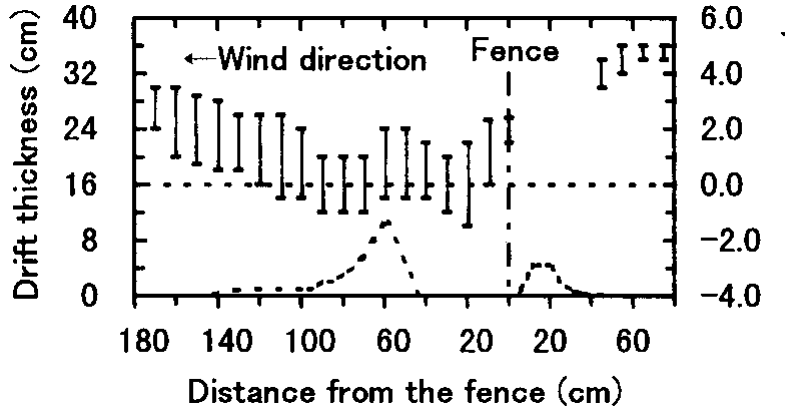

Fig. 2. A sectional diagram of the equilibrium snowdrift produced by a collector snow fence perpendicular to the wind direction, and the wind velocity at $7 \mathrm{~cm}$ height above the snow surface. The bars represent the variation range of the wind velocity.

Figure la and b show schematic diagrams of the collector and blower snow-fence models, respectively, used in this experiment. Both fences are made of aluminum. The collector snow fence consists of five slats and is $61 \mathrm{~cm}$ wide and $18 \mathrm{~cm}$ high, with a gap of $3.5 \mathrm{~cm}$ beneath the lowest slat. The blower snow fence consists of three slats inclined by $57^{\circ}$ and is $61 \mathrm{~cm}$ wide and $15.7 \mathrm{~cm}$ high, with a gap of $5.7 \mathrm{~cm}$. Three different cases were studied for both snow fences, and the resultant snowdrifts were compared. In the first case, the snow fence was perpendicular to the wind direction. In the second and third cases, the fence was tilted by $30^{\circ}$ and $45^{\circ}$.

Before the snowdrift experiment, the vertical profile of wind velocity in the wind tunnel was measured with an ultrasonic anemometer. The wind-velocity profile was measured at 42 points on the leeward side of the fence and at one point on the windward side. The measurements were made for both types of fence in the three cases mentioned above. The measurement heights were 5, 7, 9, 12, 17, 22 and $27 \mathrm{~cm}$ above the snow surface; the sampling frequency was $100 \mathrm{~Hz}$ and the sampling duration was $10 \mathrm{~s}$ at each point.

\section{RESULTS AND DISGUSSIONS}

\section{Collector snow fence}

A sectional diagram of the equilibrium snowdrift produced by a collector snow fence perpendicular to the wind direction is shown in Figure 2. The drift had a bilateral symmetry. The diagram displays the thickest section. The drift was larger on the leeward than on the windward side of the fence. The formation of snowdrift started at about $40 \mathrm{~cm}$ leeward from the fence, and the thickness rapidly became maximum (about

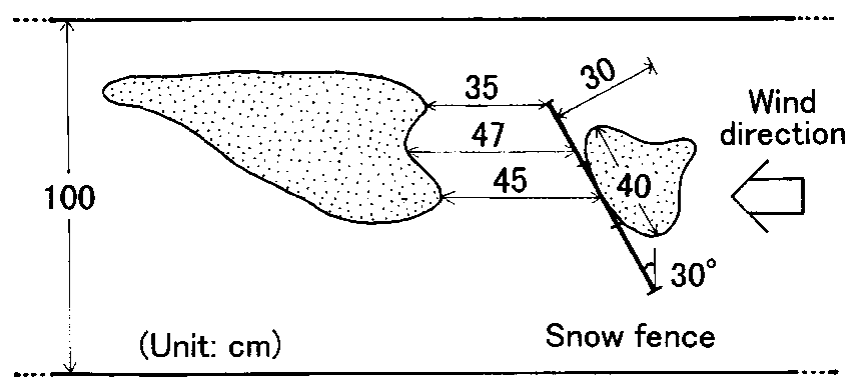

Fig. 3. Plan view of the snowdrift. It was produced when the collector snow fence was set at an angle of $30^{\circ}$.

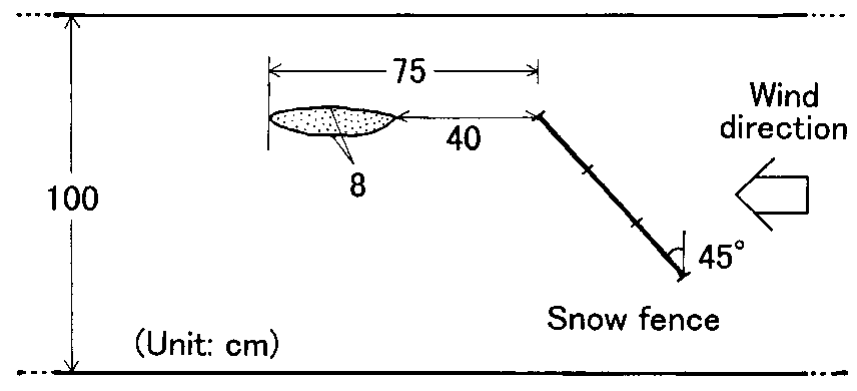

Fig. 4. Plan view of the snowdrift. It was produced when the collector snow fence was set at an angle of $45^{\circ}$.

$10.5 \mathrm{~cm})$. Then it decreased gradually on the leeward side of the peak, and the length was nearly $1 \mathrm{~m}$. On the windward side of the fence, the maximum thickness was $4.5 \mathrm{~cm}$ and the length was about $50 \mathrm{~cm}$.

The wind velocity at $7 \mathrm{~cm}$ height above the snow surface, measured at $10 \mathrm{~cm}$ intervals from $80 \mathrm{~cm}$ upwind to $170 \mathrm{~cm}$ downwind, is also shown in Figure 2. The bars represent the variation range of the wind velocity. Negative values mean that the wind flows from left to right in this figure. The wind velocity decreases to $<2 \mathrm{~ms}^{-1}$ on the leeward side of the collector snow fence. The drift was produced where the wind velocity was small, but was not produced near the fence due to the strong airflow passing through the gap. The formation of snowdrift started where both the turbulence and the velocity were small. The wind velocity increased at about $90 \mathrm{~cm}$ from the fence, and the thickness of snowdrift
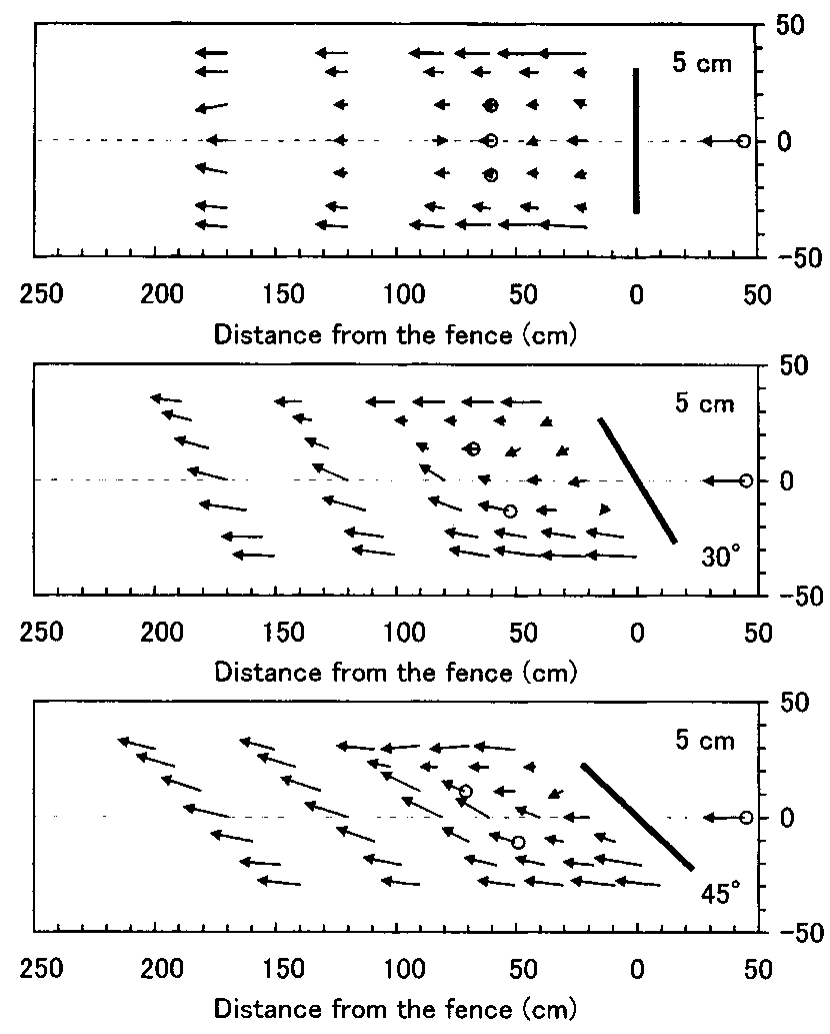

Fig. 5. The horizontal wind at $5 \mathrm{~cm}$ height. The solid line represents the collector snow fence. The root of the arrow shows the measurement position. The arrow visualizes the windvelocity vector, and the size of the arrow at the windward side represents $5.6 \mathrm{~m} \mathrm{~s}^{-1}$. (This measurement was actually made at $200 \mathrm{~cm}$ upwind from the fence.) The circles represent the positions where the Figure 6 profiles were measured. 

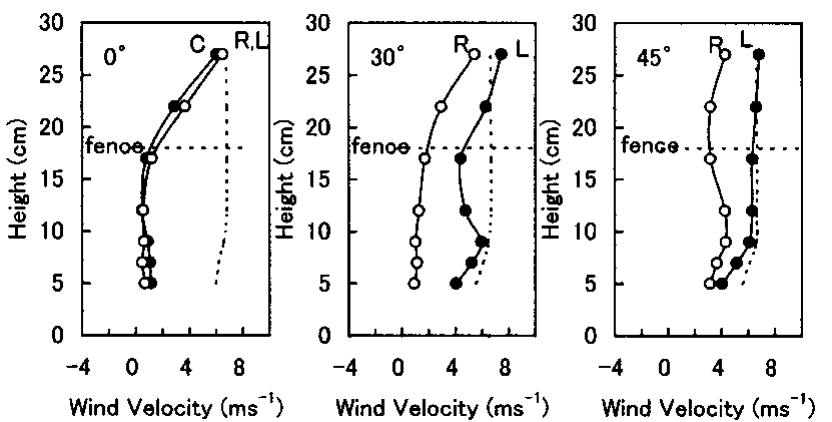

Fig. 6. Wind-velocity profiles at $60 \mathrm{~cm}$ from the collector snow fence. The dotted line is the profile on the windward side. $C$, center; $R$, right; L, left.

decreased correspondingly. The maximum wind velocity was $3 \mathrm{~m} \mathrm{~s}^{-1}$ where the drift disappeared.

When the collector snow fence was set at an angle of $30^{\circ}$, the equilibrium snowdrift was produced as shown in Figure 3 , which is a plan view of the snowdrift. The upper side of the figure is regarded as the right side of the wind tunnel in this paper. The drift was large on the right along the fence, and there was almost no drift on the left side. The maximum thickness was about $6 \mathrm{~cm}$, half the value in the perpendicular case. The mean distance from the fence to the drift was about $40 \mathrm{~cm}$, equal to that in the perpendicular case.

When the collector snow fence was set at an angle of $45^{\circ}$, an equilibrium drift was produced as shown in Figure 4. A small drift (the longer axis was $35 \mathrm{~cm}$, the shorter axis $8 \mathrm{~cm}$ and the maximum thickness $1.5 \mathrm{~cm}$ ) was produced at about $40 \mathrm{~cm}$ leeward from the right edge of the fence. Thus, when the fence was tilted, the amounts of drifted snow by the fence were much smaller than in the case of the perpendicular fence.

The horizontal wind at $5 \mathrm{~cm}$ height is shown in Figure 5. The wind velocity at the windward point was $5.6 \mathrm{~m} \mathrm{~s}^{-1}$. (Actually, this measurement was made at $200 \mathrm{~cm}$ upwind from the fence.) When the fence was perpendicular to the wind, the wind velocity at the leeward side was decreased over the whole width of the fence. When the fence was tilted, the wind velocity did not decrease on the left of the leeward side, since a wind flow from left to right occurred. As a result of this wind flow, the drift was produced only on the right, and the amounts of drifted snow decreased as the tilt angle of the fence was increased.

In Figure 6, the wind-velocity profiles at $60 \mathrm{~cm}$ leeward from the fence are compared among the three points, right, left and center, the positions of which are indicated by circles in Figure 5. When the fence was perpendicular, the profiles were very similar both at the center and at the right (or left). The wind velocity below the top of the fence was $<1 \mathrm{~m} \mathrm{~s}^{-1}$. When the fence was tilted by $30^{\circ}$, the profiles were very different at the right and left sides. The wind velocity below the top of the fence was small (about $1 \mathrm{~m} \mathrm{~s}^{-1}$ ) on the right, but was $>4 \mathrm{~m} \mathrm{~s}^{-1}$ on the left. When the fence was tilted by $45^{\circ}$, it had almost no effect on the profile on the left side, and the effect on the right near the snow surface was small. Accordingly, it was confirmed that snow accumulation by the collector snow fence at its leeward side decreased sharply when the fence was tilted.

\section{Blower snow fence}

A sectional diagram of the equilibrium snowdrift produced

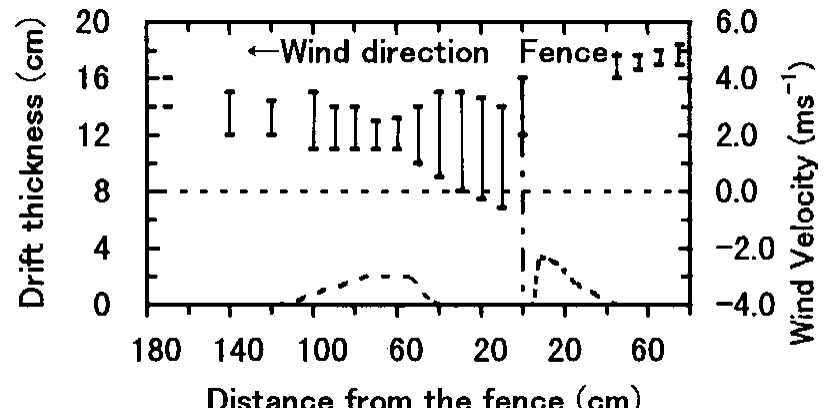

Fig. 7. A sectional diagram of the equilibrium snowdrift produced by a blower snow fence perpendicular to the wind direction, and the wind velocity at $7 \mathrm{~cm}$ height above the snow surface. The bars indicate the variation range of the wind velocity.

by a blower snow fence perpendicular to the wind direction is shown in Figure 7. In spite of the blower fence, small drifts were produced on both sides of the fence with thickness of 2 and $3 \mathrm{~cm}$, respectively. The wind velocity at $7 \mathrm{~cm}$ height above the snow surface, measured at $10 \mathrm{~cm}$ intervals from $80 \mathrm{~cm}$ upwind to $170 \mathrm{~cm}$ downwind, is also shown in Figure 7. The bars represent the variation range as in the case of the collector snow fence (Fig. 2).

The decrease of wind velocity caused by the blower snow fence was small, so no large snowdrift was produced. However, the maximum wind velocity began to decrease, as did the variation range, at about $50 \mathrm{~cm}$ downwind from the fence; this explains why a very small snowdrift was produced.
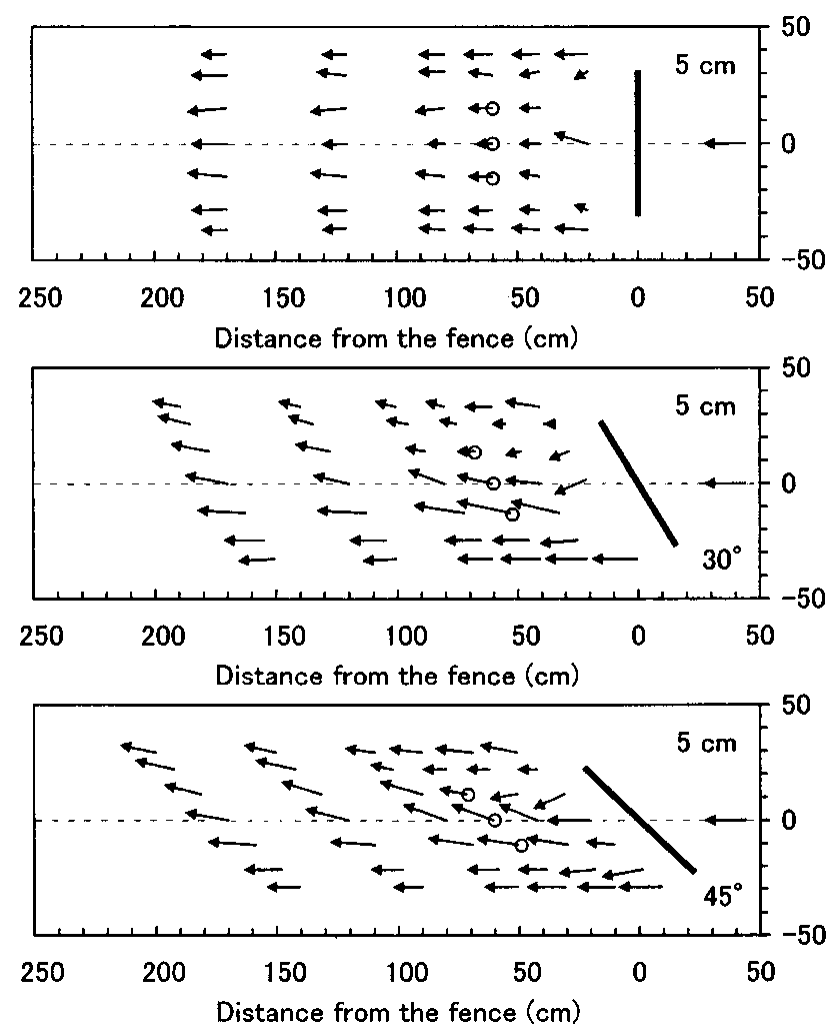

Fig. 8. The horizontal wind at $5 \mathrm{~cm}$ height. The solid line represents the blower snow fence. The root of the arrow shows the measurement position. The arrow visualizes the wind velocity vector, and the size of the arrow at the windward side represents $5.6 \mathrm{~m} \mathrm{~s}^{-1}$. (This measurement was actually made at $200 \mathrm{~cm}$ upwind from the fence.) The circles represent the positions where the Figure 9 profiles were measured. 


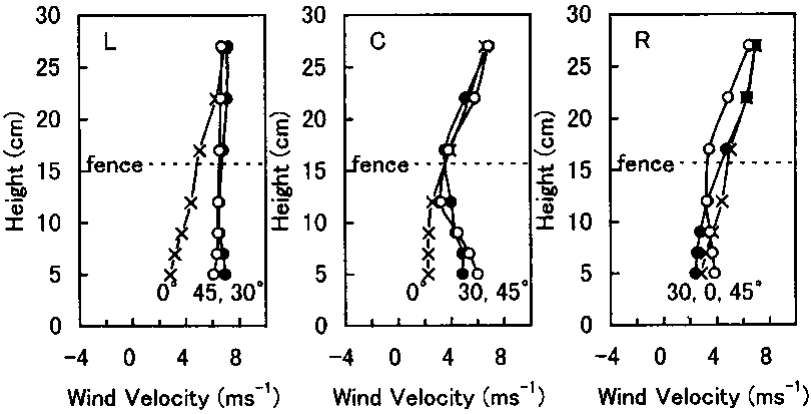

Fig. 9. Wind-velocity profiles at $60 \mathrm{~cm}$ from the blower snow fence. $\times$ : the fence was perpendicular to the wind direction. - : the fence tilt was $30^{\circ} . \bigcirc$ : the fence tilt was $45^{\circ} . C$, center; $R$, right; L, left.

When the blower snow fence was set at an angle of $30^{\circ}$, snowdrift was not produced. Since there were gaps of about $25 \mathrm{~cm}$ between the fence and the side wall of the wind tunnel because the wind tunnel and the fence were $1 \mathrm{~m}$ and $61 \mathrm{~cm}$ wide, respectively, most of the supplied snow particles may have passed through these gaps. To verify this, an additional experiment was carried out where the gaps were closed with another similar fence. The result was the same as described above. Moreover, even with the higher wind of $10 \mathrm{~m} \mathrm{~s}^{-1}$, no drift was observed. Needless to say, setting the fence at an angle of $45^{\circ}$ produces the same result.

The horizontal wind at $5 \mathrm{~cm}$ height is shown in Figure 8. The wind velocity at the windward point was $5.6 \mathrm{~m} \mathrm{~s}^{-1}$, measured $200 \mathrm{~cm}$ upstream from the fence. In the case of $0^{\circ}$ and $30^{\circ}$ tilt angles, the data are missing at the blank spaces in the row which is $20 \mathrm{~cm}$ from the fence. When the fence was tilted, the wind flow from left to right occurred and the wind velocity increased as the fence tilt increased.

In Figure 9, the wind-velocity profiles at $60 \mathrm{~cm}$ leeward from the fence are compared. The positions of right, left and center are shown as circles in Figure 8. On the right, there is little difference between the three cases. On the left side and at the center, the wind velocity was larger when the fence was tilted, which is remarkable near the snow surface.

In this experiment, a small drift was produced by the blower snow fence when it was perpendicular to the wind direction, but no drift was produced when it was set at angles of $30^{\circ}$ and $45^{\circ}$. This result means that the blowing effect of the blower snow fence increases with the setting angle.

In this experiment, large amounts of snow were deposited along the wind-tunnel wall. If many blower snow fences are set along the roads, the question arises where the blown snow will be deposited. To ascertain the most effective setting method for blower snow fences, this problem must be solved.

\section{SUMMARY}

To determine the effect of wind direction on drift control by snow fences, snowdrifting processes and wind profiles were investigated in a cold wind tunnel using a collector and a blower snow fence. Results are summarized as follows:

(1) Snow accumulation by the collector snow fence decreased sharply when the fence was set at an angle to the wind direction, because the area with weak wind velocity was reduced to half behind the tilted fence.

(2) The blowing effect of the blower snow fence increased when it was set at an angle to the wind direction.

Single snow fences were set in this experiment, and the results will help to explain the edge effect of several fences in a row.

\section{ACKNOWLEDGEMENTS}

This is a joint study of the Research Institute for Hazards in Snowy Areas, Niigata University, NIED and Heilongjiang Communications College, China. The experiment was carried out in a wind tunnel in the cold room of the Shinjo Branch of Snow and Ice Studies, NIED. The authors thank T. Takeda from NIED for his invaluable assistance with running the system in the cold room. They are also grateful to D. Issler of NaDesCoR, D. Font of Universitat de Barcelona, Spain, and I. Gürer of Gazi University, Turkey, for useful comments on the manuscript, and to M. Otsuki, who was a student of Niigata University, for his support during the experiment.

\section{REFERENCES}

Anno, Y. 1984. Requirements for modeling of a snowdrift. Cold Reg. Sci. Technol., $\mathbf{8}(3), 241-252$.

Anno, Y. and T. Konishi. 1981. Modelling the effects of a snowdrift-preventing forest and a snow fence by means of activated clay particles. Cold Reg. Sci. Technol., 5(1), 43-58.

Naruse, R. 1982. [The shape of snow drifts and distribution of wind speed around the fence.] Low Temp. Sci., Ser. A 41, 65-73. [In Japanese with English summary.]

Sato, T., K. Kosugi and A. Sato. 2001. Saltation layer structure of drifting snow observed in wind tunnel. Ann. Glaciol., 32 (see paper in this volume).

Shiotani, M. 1967. [Snow fences.] Seppyo, 7. Jpn. Soc. Snow Ice, 29(4), 100-106. [InJapanese.]

Tabler, R. D. 1980a. Geometry and density of drifts formed by snow fences. f. Glaciol., 26(94), 405-419.

Tabler, R. D. 1980b. Self-similarity of wind profiles in blowing snow allows outdoor modeling. F. Glaciol., 26(94), 421-434.

Takeuchi, M. 1989. Snow-collection mechanisms and the capacities of snow fences. Ann. Glaciol., 13, 248-25l.

Takeuchi, M., K. Ishimoto, T. Nohara and Y. Fukuzawa. 1984. [Study of snow fence.] Yuki to doro [Snow and roads ], 1, 96-100. [In Japanese.]

Uematsu, T., T. Nakata, K. Takeuchi, Y. Arisawa and Y. Kaneda. 1991. Three-dimensional numerical simulation of snowdrift. Cold Reg. Sci. Technol., 20(1), 65-73.

Verge, R.W. and G. P. Williams. 1981. Drift control. In Gray, D. M. and D. H. Male, eds. Handbook of snow: principles, processes, management and use. Toronto, Ont., Pergamon Press Canada Ltd., 630-647.

Wang Zhonglong and Chen Yuan. 1980. Research on prevention of snowdrifts by blower fences. 7. Glaciol., 26(94), 435-445. 